\title{
WASTEWATER TREATMENT WITH BIOCONVERSION FOR MOTOR FUEL PRODUCTION
}

\author{
Sergii Shamanskyi ${ }^{1}$, Sergii Boichenko ${ }^{2}$, Lesia Pavliukh ${ }^{3}$ \\ ${ }^{1}$ Research Department, National Aviation University, Kyiv, Ukraine \\ shamanskiy_s_i@ukr.net \\ ORCID: http://orcid.org/0000-0002-6215-3438 \\ ${ }^{2}$ National Aviation University, Kyiv, Ukraine \\ chemmotology@ukr.net \\ ORCID: http://orcid.org/0000-0002-1196-3852 \\ ${ }^{3}$ Department of Ecology, National Aviation University, Kyiv, Ukraine \\ lenyo@ukr.net \\ ORCID: http://orcid.org/0000-0002-7715-4601
}

ABS TRACT

Article history:

Received date 07.09.2020

Accepted date 12.10.2020

Published date 30.10 .2020

Section:

Waste Management and Disposal

DOI

$10.21303 / 2313-8416.2020 .001460$

KEYWORDS

motor biofuel

microalgae

wastewater treatment

economic efficiency

nitrogen compounds

phosphorous compounds

bioconversion

photobioreactor
The object of research: the process of wastewater treatment using bioconversion for subsequent motor fuel production.

Investigated problem: improving the efficiency of bioconversion process for biofuel production with simultaneous wastewater treatment by removing nitrogen and phosphorous compounds.

The main scientific results: providing the possibility of biofuel production with energy and economic inefficiency. It is done by combining the process of motor biofuel production with the process of treating wastewater from biogenic elements makes it perspective for commercial use. Traditional technology for the production of motor biofuels from microalgae includes cultivation, harvesting, dehydration and drying of biomass, extraction of oils from them and subsequent production of methyl esters and glycerol. Such technology is often not economically effective. It requires significant amount of energy for carrying out all necessary processes. In addition, it requires significant expenditures of water and nutrients. The use of nutrient-rich wastewater as a culture medium for the cultivation of microalgae allows not only to reduce costs, but also to purify wastewater from nitrogen and phosphorus compounds, which makes this process economically effective.

The area of practical use of the research results: Sewage and gray water treatment plants. Industrial and agricultural effluents treatment plants. Different types of enterprises, which have wastewater enriched with nitrogen and phosphorous compounds.

Innovative technological product: The technology of microalgae cultivation using wastewater as a culture medium. The technology allows effectively purifying used wastewaters from nitrogen and phosphorous compounds with no waste at the end.

Scope of the innovative technological product: Improved technology of motor biofuel production with simultaneous wastewater purification, which is economically effective and environmentally safe.

(C) The Author(s) 2020. This is an open access article under the CC BY license http://creativecommons.org/licenses/by/4.0).

\section{Introduction}

\section{1. The object of research}

The object of research is the process of wastewater treatment, in particular wastewater purification from nitrogen and phosphorous compounds using bioconversion.

\section{2. Problem description}

Energy consumption is increasing constantly [1]. At the same time, quality of traditional fuel is deteriorating. Progress in means of combustion products purification does not keep up with the increasing amount of harmful substances formed during energy production. As a result, the damage to the environment is becoming more significant. In addition, if humanity continues to consume fossil fuels at the current level (despite the steady increase in population), known oil and gas reserves may be depleted in the 2050s-2060s. Therefore, the search for alternative fuels undoubtedly comes to the fore today.

Bioconversion is the process of converting one chemical compound into another with the required chemical characteristics, with the participation of microorganisms. Its main processes are ox- 
idation, condensation, decomposition and hydrolytic reactions. In addition to bioconversion of chemical compounds, bioconversion of solar energy is possible. This is the conversion of solar energy into chemical energy of organic matter in the form of biomass, through photosynthesis. In this case, solar energy is stored in the form of chemical energy, which can then be released in various ways.

\section{3. Suggested solution to the problem}

Photoelectric transformations are performed by semiconductor and other elements with diode properties, i.e. a combination of $\mathrm{p}-\mathrm{n}$ type semiconductors ( $\mathrm{p}-\mathrm{n}$ junction). There is separation of negatively charged electrons and positively charged holes takes place as a result of photon absorption under the action of solar radiation at the contact boundary of semiconductors, resulting in photo- electromotive force [2]. One of the disadvantages of this method is relatively low efficiency (15-20\%) and inconvenience of accumulation and storage of electricity, given that the flow of solar radiation is not uniform.

Thermodynamic transformations occur in accordance with thermodynamic cycles. Such transducers include: systems for capturing solar radiation and its concentration; systems for receiving radiation, which converts its energy into heat, which is transferred to heat carrier; heat exchangers that form a hot and a cold source of a heat engine. Solar energy can be converted directly into thermal, mechanical or electrical energy with the help of thermodynamic cycles. The efficiency of such transformations depends on many factors. It's mostly higher than for photovoltaic cells, but generally not very high. Additionally, the converters can have heat accumulators to store thermal energy, which only partially smooths out the uneven flow of solar energy. Moreover, heat accumulators are quite expensive.

Conversion of energy into biomass [3] is the conversion of radiant solar energy into chemical energy of biomass through traditional processes of photosynthesis. These processes occur constantly in nature. Their result is the planetary biomass of major producers. This mass is $1.8 \cdot 10^{12}$ tons of dry matter, which stores $3 \cdot 10^{22} \mathrm{~J}$ of chemical energy. Under artificial conditions, this can be done by introducing special technologies for growing biomass. Its chemical energy can be converted into other types and used to meet energy needs. The most promising transformation is the production of such types of fuel from biomass (biodiesel, bioethanol, biogas, etc.), which can be used to obtain useful energy in conventional internal combustion engines. Given this, the most promising types of energy producers can be considered oil crops with high content of hydrocarbons in the oil [4]. They can be divided into soil crops (rapeseed, sugar cane, etc.) and aquatic crops (varieties of algae and microalgae).

The disadvantage of growing soil crops is the need to allocate significant fertile areas, which could otherwise be used for growing food crops.

The advantage of aquatic energy crops is that they can be grown using only small areas of land, which can be completely barren. Among aquatic crops, microalgae deserve special attention. They inhabit places with high humidity. The main natural places of their reproduction are swamps, lakes, other reservoirs, including salt ones. Growth of microalgae, as well as the growth of other photosynthetic organisms, requires such components as light, carbon dioxide, biogenic compounds and heat. Some of them have fairly high growth rate and, despite the small size of individuals (from 2 to 50 microns), can double their biomass up to 8 times a day under favorable conditions [5]. The yield of the finished product (oil saturated with hydrocarbons) can reach $80 \%$ of their initial mass. Some cultures of microalgae are more than 20 times more valuable than palm oil and almost 120 times more valuable than rapeseed oil in terms of energy containing products, which can be obtained out from them. Finished products do not contain sulfur (as petroleum fuels), do not contain toxic substances (such as lead) and are well decomposed by microorganisms in the nature conditions. In addition, their combustion does not increase the concentration of $\mathrm{CO}_{2}$ in the atmosphere, like other types of biofuels, and, as a result, does not contribute to the development of the greenhouse effect.

Microalgae can also accumulate a variety of lipids and fatty acids, which are also valuable products. In addition, the significant content of fats, which are lighter than water, provides them with buoyancy, i.e. the ability to stay close to the water surface and have more access to light.

There are technologies today for cultivating microalgae in open water and in special installations - photobioreactors or photobioconverters. 
The disadvantages of open water microalgae cultivation are possibilities to carry out the process only during the warm season and in the presence of sufficient sun irradiation. Therefore, such technology can be effectively used only in areas with warm climate. Cultivating processes can also be negatively affected by other weather factors, uncontrolled changes in the properties of the environment (water), such as its pollution, the appearance of various organisms in the water, changes in acidity, and so on. In addition, it is difficult to automate the processes of cultivation and harvesting in open water.

The technology of cultivation in bioreactors, as a rule, does not have these shortcomings. There are photobioreactors of various designs. Here are the main ones [6].

Photobioreactors, shaped in the form of open troughs with a relatively thin layer of water, in which algae are placed. Despite their advantages (the possibility to create an optimal environment for cultivating, efficient mixing, automation, etc.), they have a number of disadvantages inherent in open water bodies (for example, the impact of adverse weather conditions).

Photobioreactors, shaped in the form of transparent flasks and tubes filled with cultivating medium and algae. Such installations are less sensitive to weather conditions, but have other disadvantages. Access to the light required for photosynthesis through transparent walls is complicated over time due to plaque on the walls, which is formed inside, and the mass of microalgae near the walls also complicates the passage of light inside, as the number of microalgae increases.

Photobioreactors, shaped in the form of large tanks made out of transparent material. In general, they usually need artificial lighting because light does not penetrate well into the thickness of microalgae, even when mixing takes place.

Photobioreactors, shaped in the form of pyramidal containers, which are open horizontal troughs with cultivating medium and algae, located in a pyramidal body of transparent material. Given the advantages inherent in open troughs, these installations are not significantly affected by adverse weather factors. However, the disadvantage of such installations may be certain technological problems with the saturation of the environment with carbon dioxide and its efficient use, as well as problems with ensuring the continuity of the cultivation process.

The aim of the research is to show by economic calculation that combining the process of microalgae cultivation for biofuel production with the process of wastewater purification from nitrogen and phosphorous compounds makes the technology economically inefficient.

\section{Materials and Methods}

The authors propose a number of microalgae strains, based on the analysis of the properties of microalgae biomass growth, as well as the accumulation of lipids in them, suitable for cultivation for the subsequent production of motor biofuel. Among them, strains of Botryococcus Braunii and Chlorella Vulgaris may deserve special attention [7].

Specificity of Botryococcus Braunii strain is that the dry mass of these algae has a high content of hydrocarbons, which varies depending on the race. Therefore, they can be considered as a potential source of renewable fuel.

According to the characteristics of containing their dry weight hydrocarbons, there are three races of Botryococcus Braunii:

- race $A$ - the hydrocarbon content is about $61 \%$ of dry weight;

- race $B$ - the hydrocarbon content varies from $26 \%$ to $86 \%$ of dry weight;

- race $L$ - the hydrocarbon content of 2-8\% of dry weight.

These three races differ in some morphological and physiological characteristics (Table 1).

It is possible to conclude that the most promising and interesting for research are algae races $A$ and $B$, because of having high content of hydrocarbons.

Another positive feature is that the hydrocarbons, obtained from Botryococcus Braunii have a high octane number. So, they can be used as fuel for various modes of transport.

However, these algae have some drawbacks. First, their growth rate is low, which creates the problem of their use on an industrial scale $[8,9]$. To increase the rate of growth, it is necessary to create the optimal temperature, ensure the content of nutrients in the water and provide other favorable conditions.

Secondly, the known plants for their cultivation are not effective enough. In view of the above, it is necessary to conduct further research to find new efficient designs of solar energy 
plants that can provide the most favorable conditions for the process of bioconversion of solar energy, namely the cultivation of algae Botryococcus Braunii.

Table 1

Distinctive characteristics of Botryococcus Braunii races

\begin{tabular}{|c|c|c|c|c|}
\hline No & Characteristics of Botryococcus Braunii races & Race A & Race B & Race $\mathbf{L}$ \\
\hline 1 & Nature of hydrocarbons & $\begin{array}{c}\mathrm{C}_{25}-\mathrm{C}_{31} \text { odd n-alka- } \\
\text { dienes }\end{array}$ & $\begin{array}{l}\text { Triterpenes } \mathrm{C}_{\mathrm{n}} \mathrm{H}_{2 \mathrm{n}-10}, \\
\quad n=30-37\end{array}$ & Tetraterpenes $\mathrm{C}_{40} \mathrm{H}_{78}$ \\
\hline 2 & Color of the colony stationary phases & Pale yellow or green & \multicolumn{2}{|c|}{$\begin{array}{l}\text { Orange-red or orange-brown due to the accumula- } \\
\text { tion of carotenoids }\end{array}$} \\
\hline 3 & Long chain phenols of alkenes & Present & Absent & Absent \\
\hline 4 & Nature of biopolymers & $\begin{array}{l}\text { Very long aliphatic ch } \\
\text { ric bridges }\end{array}$ & $\begin{array}{l}\text { ins, connected by ethe- } \\
\text { d fatty ethers }\end{array}$ & $\begin{array}{l}\text { Tetraterpenoid, connected } \\
\text { by etheric bridges }\end{array}$ \\
\hline
\end{tabular}

\section{Results}

Conventional technology for biodiesel production out of microalgae includes cultivation, harvesting, dehydration and drying of biomass, extraction of oils and further processing to obtain methyl esters and glycerin. Residual biomass (after extraction of oils) contains a significant part of organic matter and can be used for biogas production. This significantly increases the energy value of microalgae.

Cultivation process require energy, first of all electricity. According to the existing technologies, specific consumption of electricity during cultivation in open photobioreactors is about $1 \mathrm{~W} / \mathrm{m}^{2}$ of the cultivating area, for closed photobioreactors $-5 \mathrm{~W} / \mathrm{m}^{2}$.

The microalgae cells must be collected and dehydrated after cultivation. Filtration or centrifugation can be used for this purpose. There is a sufficient amount of equipment on the market to perform this processes, because necessity for dehydration of microorganisms often arises in various areas of economic activity.

The average values of energy costs per $1 \mathrm{~m}^{3}$ of culture medium, according to open sources, are: filter presses $-1.8 \mathrm{MJ} / \mathrm{m}^{3}$ (degree of dehydration $80 \%$ ); centrifuges $-3,6 \ldots 14,4 \mathrm{MJ} / \mathrm{m}^{3}$ (degree of dehydration of $90 \%$ ).

The efficiency of removing oils from the dehydrated biomass of microalgae is $90 \%$. The energy required to extract oils from dehydrated biomass at large production volumes can be taken by analogy with the production of rapeseed oil from the initial biomass. The average specific energy cost per one kilogram of oil obtained is: $0.35 \mathrm{MJ} / \mathrm{kg}$ of electricity; $1.75 \mathrm{MJ} / \mathrm{kg}$ of thermal energy.

Energy efficiency of processing oils obtained from microalgae into biodiesel is $90 \%$. The average specific energy costs for the production of one $\mathrm{kg}$ of biodiesel, for large production volumes, can also be estimated by the existing conventional technologies: $0.043 \mathrm{MJ} / \mathrm{kg}$ of electricity and $0.75 \mathrm{MJ} / \mathrm{kg}$ of thermal energy.

The energy efficiency of processing the residual biomass of microalgae (after removal of oils) into biogas is $90 \%$. The average specific energy costs for the production of one normal $\mathrm{m}^{3}$ of biogas can be estimated according to the existing conventional technologies and are: $0.48 \mathrm{MJ} / \mathrm{m}^{3}$ of electricity and $1.5 \mathrm{MJ} / \mathrm{m}^{3}$ of heat.

The total amount of potentially obtained energy stored in energy sources made out of cultivated microalgae (biodiesel and biogas) is: for closed photobioreactors $-267.1 \mathrm{MJ} / \mathrm{m}^{2}$; for open photobioreactors $-76.41 \mathrm{MJ} / \mathrm{m}^{2}$.

The total amount of potentially used electrical and thermal energy, respectively, spent on the microalgae cultivation and biofuels production out of them is: for closed photobioreactors $172.38 \mathrm{MJ} / \mathrm{m}^{2}$ and $19.72 \mathrm{MJ} / \mathrm{m}^{2}$; for open photobioreactors $-44.43 \mathrm{MJ} / \mathrm{m}^{2}$ and $5.65 \mathrm{MJ} / \mathrm{m}^{2}$.

The percentage of energy that is spent on biofuel production in relation to the energy stored in biofuel itself is: for closed photobioreactors $-72 \%$; for open photobioreactors $-66 \%$

A positive energy balance changes to a negative one, assuming that the electricity consumed is generated by thermal power plants, given their low efficiency. Let us assume that the electricity is generated at a thermal power plant with cogeneration, which operates with efficiency of $60 \%$. The amount of energy that is actually contained in the consumed electrical energy is: for closed photobioreactors $-287.3 \mathrm{MJ} / \mathrm{m}^{2}$; for open photobioreactors $-74.05 \mathrm{MJ} / \mathrm{m}^{2}$. 
The percentage of energy consumed in relation to store in biofuels in this case will be: for closed photobioreactors $-115 \%$; for open photobioreactors $-104 \%$. Thus, the production of biofuels from microalgae becomes energy and economically inefficient.

Biogenic are chemical elements that are permanent part of living organisms and perform certain biological functions in them. Biogenic elements include: oxygen, carbon, hydrogen, nitrogen, phosphorus, boron, sulfur, calcium, potassium, sodium, chlorine, as well as iodine, zinc, magnesium, manganese, iron and other chemical elements needed by organisms in small quantities.

An important resource necessary for the cultivation of microalgae is water, as the basis of the culture medium. Practice shows that the use of wastewater as the basis for the culture medium makes it possible to reduce the consumption of clean water for these purposes up to $90 \%$. In this case, the wastewater must be pre-treated, primarily to make it transparent.

\section{Discussion}

The main biogenic elements in municipal wastewater are nitrogen and phosphorus, which are in the form of various compounds. These compounds, getting into water bodies, lead to their eutrophication. They increase the rate of phytoplankton development on the water surface. It reduces the water permeability to light and oxygen. Insufficient light intensity leads to inhibition of deep plants growth and to their death. Insufficient oxygen amount causes the death of other aquatic organisms.

The consequence of eutrophication is not only the death of fish in water bodies used for fishery, but also lead to a decrease in environmental safety if the water bodies are used for recreational purposes (for water tourism), or as a source of drinking water. Cyanobacteria (blue-green algae) that accumulate on the surface of a water body produce secondary metabolites such as a wide range of toxins known as cyanotoxins. They are often considered pathogenic despite not developing in the body because they have the potential to adversely affect human health.

Production of motor biofuels from plant raw materials is considered very promising [10]. There are several generations of biofuels depending on the biological raw materials from which it can be made. The first generation - made from the biomass of soil plants specially cultivated for these purposes. The second generation - made from biomass waste. The third generation - made from the biomass of specially cultivated aquatic plants. Many researchers show that the most promising for the biofuel production can be microalgae due to their rapid growth rate and high lipid content of their biomass [11]. However, the authors often do not take into account the economic component. The cycle of biofuel production, starting from the cultivation of biomass to the finished product, includes many technological processes with significant energy and, consequently, economic costs [12-14]. If the economic component is taken into account, then the calculations by aggregated indicators, taking into account the costs of the entire production chain up to the finished product, the process is not profitable [15]. Energy and economic costs of fuel production exceed the energy and economic benefits of selling such fuel.

Practice shows that household wastewater that has undergone mechanical and biological treatment at conventional sewage treatment plants contains a large number of nitrogen and phosphorus compounds. Their concentration at the outlet of the treatment plant is not constant, but varies depending on many factors.

Microalgae are good absorbers of biogenic elements (phosphorus and nitrogen compounds are used in photosynthesis) [16]. Many studies show a fairly high efficiency of nitrates and phosphates removal out of wastewaters during their treatment by metabolism of microalgae $[17,18]$. However, many authors also do not take into account the economic component and do not show any economic efficiency. The purification process is long-lasting and requires treatment facilities of large sizes. Despite the technical efficiency, this often makes such treatment economically unfounded.

Thus, the process of cultivating raw materials for the production of motor biofuel can be combined with the process of treating wastewater from biogenic elements. This combination takes advantage of both processes and reduces overall energy and economic costs. The process in this case becomes economically viable and preventing eutrophication of water bodies.

The main feature of the study is to confirm the prospects for the production of motor biofuels out of microalgae biomass. Despite the significant costs of cultivation and production process, which are estimated to exceed the profit from the sale of the fuel received, the ways, which can 
change it, are shown. A common trend in the technological processes that are being developed is the reduction of the use of new resources and the reduction of waste generated. The use of secondary resources, such as wastewater, significantly reduces the cost of the technological process, and the manufacture of additional products along with the main one. It allows not only the reduction or complete elimination of waste, but also the possibility of getting additional profits from the sale of additional products. This makes it possible to turn the unprofitable process of biofuel production into a profitable one while reducing the negative impact on the environment.

The advantage of the study is the use of an approach to solving the problem, which provides the absence of waste. One of the processes of the proposed technology is wastewater treatment. The waste of this treatment is biomass of microalgae, which is considered as raw material that then can be used for producing biofuels and other additional products.

Microalgae based biofuel production has also some restriction. Not all strains of microalgae that can absorb contaminants from wastewater pretty well, including nitrogen and phosphorus compounds, can be considered as raw materials for biofuels due to the insufficient content of lipids in their biomass. In addition, not all wastewater can be used as culture medium. Some types of industrial effluents can have significant concentrations of toxic elements, including heavy metals. When cultivating microalgae in such media, their biomass is saturated with these elements and becomes unsuitable for the production of motor fuels or other products. Therefore, among the limitations we can name the necessity to apply only strains of microalgae with high content of lipids, as well as to use wastewater with low concentrations of toxic substances.

The question arises of increasing the efficiency of cultivation in the future by increasing biomass growth rate and increasing the rate of lipid accumulation. The direction of further research should primarily be the search for strains of microalgae with the highest efficiency of biogenic elements absorption. Such strains must also have a high rate of biomass growth, high lipid content of the biomass, and be undemanding to the cultivation conditions. On the other hand, the direction of further research should also be the search for optimal cultivation conditions for the development of highly efficient production technologies.

\section{Conclusions}

Given the constant rise in prices for traditional energy sources, the problem of finding alternatives is one of the most actual. Solar energy, as an alternative source, has been used in various countries around the world for a long time. One of the most interesting technologies for the use of solar energy is its bioconversion, which is a relatively new but promising technology. This study can make a significant contribution to solving energy problems in the future.

Obtaining hydrocarbon fuels through bioconversion of solar energy is also a promising way to develop alternative energy in many countries, which can increase the country's energy independence and significantly reduce the negative impact on the environment associated with the use of coal and petroleum products.

\section{References}

[1] Karpov, K. A. (2019). Development Trends of Global Energy Consumption. Studies on Russian Economic Development, 30 (1), 38-43. doi: http://doi.org/10.1134/s1075700719010088

[2] Yousif, E. M. (2015). The Photoelectric Effects: Radiation Based With Atomic Model. International Journal of Fundamental Physical Sciences, 5 (1), 18-31. doi: http://doi.org/10.14331/ijfps.2015.330082

[3] Shamanskii, S. I., Nestorjak, D. M. (2012). Bioconversion of Solar Energy as a Perspective Direction in Alternative Energy. Green Energy. Kyiv, 371-372.

[4] Nigatu Gebremariam, S., Mario Marchetti, J. (2017). Biodiesel production technologies: review. AIMS Energy, 5 (3), $425-457$. doi: http://doi.org/10.3934/energy.2017.3.425

[5] Bhagea, R., Bhoyroo, V., Puchooa, D. (2019). Microalgae: the next best alternative to fossil fuels after biomass. A review. Microbiology Research, 10 (1), 12-24. doi: http://doi.org/10.4081/mr.2019.7936

[6] Shamanskyi, S., Boichenko, S., Adeniyi, C. (2019). Photobioreactor for microalgae cultivation for biofuel production with simultaneous sewage water treatment. Systemy i Środki Transportu Samochodnego. Wybrane Zagadnienia. 16. Seria: Transport. Rzeszów: Politechnika Rzeszowska, 61-67.

[7] Sasikanth, K., Jyotsna, T., Anjali, P., Sharma, M. C. (2014). Studies on cultivation of lipid accumulating Botryococcus Braunii from North Gujarat inland waters for generation of 3rd generation biofuels. Indian journal of applied research, 4 (9), 31-35. 
[8] Tran, H.-D., Do, T.-T., Le, T.-L., Nguyen, M.-L. T., Pham, C.-H. et. al. (2019). Cultivation of Haematococcus pluvialis for astaxanthin production on angled bench-scale and large-scale biofilm-based photobioreactors. Vietnam Journal of Science, Technology and Engineering, 61 (3), 61-70. doi: http://doi.org/10.31276/vjste.61(3).61-70

[9] Silva, C. E. de F., Gris, B., Bertucco, A. (2016). Simulation of microalgal growth in a continuous photobioreactor with sedimentation and partial biomass recycling. Brazilian Journal of Chemical Engineering, 33 (4), 773-781. doi: http://doi.org/ 10.1590/0104-6632.20160334s20150016

[10] Soh, L., Zimmerman, J. (2011). Biodiesel production: the potential of algal lipids extracted with supercritical carbon dioxide. Green Chemistry, 13 (6), 1422-1429. doi: http://doi.org/10.1039/c1gc15068e

[11] Pruvost, J., Van Vooren, G., Le Gouic, B., Couzinet-Mossion, A., Legrand, J. (2011). Systematic investigation of biomass and lipid productivity by microalgae in photobioreactors for biodiesel application. Bioresource Technology, 102 (1), $150-158$. doi: http://doi.org/10.1016/j.biortech.2010.06.153

[12] Posten, C. (2007). Principles of Mechanical Bioseparation. Kaiserstraße: Shaker Verlag.

[13] Uduman, N., Qi, Y., Danquah, M. K., Forde, G. M., Hoadley, A. (2010). Dewatering of microalgal cultures: A major bottleneck to algae-based fuels. Journal of Renewable and Sustainable Energy, 2 (1). doi: http://doi.org/10.1063/1.3294480

[14] González-Fernández, C., Ballesteros, M. (2012). Microalgae autoflocculation: an alternative to high-energy consuming harvesting methods. Journal of Applied Phycology, 25 (4), 991-999. doi: http://doi.org/10.1007/s10811-012-9957-3

[15] Schlagermann, P., Göttlicher, G., Dillschneider, R., Rosello-Sastre, R., Posten, C. (2012). Composition of Algal Oil and Its Potential as Biofuel. Journal of Combustion, 2012, 1-14. doi: http://doi.org/10.1155/2012/285185

[16] Delgadillo-Mirquez, L., Lopes, F., Taidi, B., Pareau, D. (2016). Nitrogen and phosphate removal from wastewater with a mixed microalgae and bacteria culture. Biotechnology Reports, 11, 18-26. doi: http://doi.org/10.1016/j.btre.2016.04.003

[17] Singh, R., Birru, R., Sibi, G. (2017). Nutrient Removal Efficiencies of Chlorella vulgaris from Urban Wastewater for Reduced Eutrophication. Journal of Environmental Protection, 8 (1), 1-11. doi: http://doi.org/10.4236/jep.2017.81001

[18] Manea, R. G., Ardelean, I. I. (2016). Nitrogen and Phosphorus Removal from Municipal Wastewater Using Cinsortia of Photosynthetic Microorganisms. Scientific Bulletin. Series F. Biotechnologies, XX, 286-292. 